\title{
Spectroscopic studies of fuel recycling and impurity behaviors in the divertor region of Wendelstein 7-X
}

Yanling WEI (魏彦玲) ${ }^{1,2, a}$, Erhui WANG (王二辉) ${ }^{2}$, Yunfeng LIANG (梁云峰) ${ }^{2}$, Sebastijan BREZINSEK ${ }^{2}$, Maciej KRYCHOWIAK ${ }^{3}$, Kenneth HAMMOND ${ }^{3}$, Olaf NEUBAUER ${ }^{2}$, Ralf KÖNIG ${ }^{3}$, Stepan SEREDA ${ }^{2}$, Lukas RUDISCHHAUSER ${ }^{3}$, Michael ENDLER ${ }^{3}$, Boyd BLACKWELL ${ }^{4}$, Christian LINSMEIER $^{2}$ and $\mathrm{W}^{7}-\mathrm{X} \mathrm{Team}^{3, \mathrm{~b}}$

${ }^{1}$ Southwestern Institute of Physics, Chengdu 610041, People's Republic of China

${ }^{2}$ Forschungszentrum Jülich $\mathrm{GmbH}$, Institut für Energie- und Klimaforschung - Plasmaphysik, Partner of the Trilateral Euregio Cluster (TEC), Jülich 52425, Germany

${ }^{3}$ Max Planck Institute for Plasma Physics, Greifswald 17491, Germany

${ }^{4}$ Australian National University, Canberra ACT AUS 0200, Australia

${ }^{a}$ Email of corresponding author: y.wei@ swip.ac.cn

${ }^{b}$ Member of the W7-X Team are listed in Nucl. Fusion 53. 126001 (2013).

\begin{abstract}
:
The first divertor operation phase (OP1.2a) was carried out on Wendelstein 7-X in the second half of 2017. The fuel recycling and impurity behaviors in the divertor region were investigated by employing a newly built UV-VIS-NIR overview spectroscopy system. The characteristic spectral lines of working gases (hydrogen and helium), intrinsic impurities (carbon, oxygen and iron) and seeded impurities (neon and nitrogen) were identified and analyzed. The divertor electron temperature and density were measured using He I (667.8 $\mathrm{nm}, 706.5 \mathrm{~nm}$ and $728.1 \mathrm{~nm})$ line intensity ratios. The $\mathrm{H}_{\alpha}(656.3 \mathrm{~nm})$, He I (587.6 nm), C II $(514.5 \mathrm{~nm})$ and $\mathrm{O} I(777.2 \mathrm{~nm})$ emissions were investigated over a wide range of operating conditions. Results show that fuel and impurity emissions in divertor region exhibit a strong dependence on magnetic topology and plasma conditions. The levels for $\mathrm{H}_{\alpha}, \mathrm{He}$ I, C II and O I emissions are all reduced moving from the standard configuration to the high mirror configuration, and even further reduced for the high iota configuration, which is associated with decreasing connection length in these island divertor configurations. The H/He influx ratio shows that the plasma is a mixture of helium and hydrogen. The neutral and impurity influxes from the divertor target tend to increase with increasing divertor electron temperature.
\end{abstract}

Keywords: spectroscopy diagnostic, fuel recycling, impurity

(Some figures may appear in color only in the online journal) 


\section{Introduction}

The study of fuel recycling and impurity behaviors is a long-standing field of fusion plasma research. The plasma-wall interaction and the release of the fuel neutrals and impurities from the wall into the plasma have strong influence on the global plasma control [1-3]. It is important to control the fuel recycling and avoid impurity accumulation in improved energy confinement regimes in order to maintain stationary plasma condition. The information of fuel recycling and impurity behaviors can be provided by spectroscopy diagnostics through monitoring the characteristic spectrum of plasma neutrals and ions, and the database in this field is by far not as large and detailed for stellarator as for tokamaks. Wendelstein 7-X (W7-X) is currently the world's largest stellarator device. Its goal is to demonstrate the stellarator being an option for future fusion power plants [4]. One major question needed to be addressed is the divertor operation at high power. The W7-X stellarator makes use of the magnetic island divertor concept which utilizes magnetic islands intrinsically formed in the edge magnetic field topology induced by external coils [5-8]. The magnetic island divertors are 3D-shaped and toroidally discrete due to the non-axisymmetric magnetic field in stellarator. The target-to-target connection length in W7-X is much longer than the connection length in tokamaks. For example, W7-X is estimated to have $300 \mathrm{~m}$ of connection length, while the connection length in ASDEX Upgrade poloidal divertor is $50 \mathrm{~m}$ $[4,8]$. The island divertor concept was first tested in Wendelstein 7-AS (W7-AS) [9-11]. A new promising plasma operational regime termed as high density $\mathrm{H}$-mode (HDH) was discovered under the island configuration in W7-AS [12,13] and is being further explored in W7-X. The influence of fuel particles and impurities on island divertor performance in different island magnetic configurations is being studied to find the optimal magnetic edge topologies for high density operation.

W7-X stellarator achieved its first plasma on the $10^{\text {th }}$ of December 2015 [4, 14]. After initial limiter operation, 10 adiabatically cooling graphite divertor units, known as the test divertor units (TDU), were installed [15]. The first divertor operation phase (OP1.2a) was carried out in the second half of 2017. During this campaign, a UV-VIS-NIR spectroscopy system is employed to study the fuel particle recycling and impurity behaviors in the divertor region [16].

In the present article, we summarized the results of a series of spectral measurements in a wide range of operating conditions during OP1.2a. The experimental setup is described in section 2. The experimental results and discussion are presented in section 3. Spectral surveys were carried out for neon and nitrogen seeded plasmas. The divertor electron temperature $T_{\mathrm{e}}$ and density $n_{\mathrm{e}}$ were measured by using the He I line intensity ratios. The fuel and impurity emissions in different magnetic configurations are studied. And the dependence of impurity behaviors on plasma conditions is analyzed. Summary can be found in section 4 . 


\section{Experimental setup}

The magnetic field configuration of $\mathrm{W} 7-\mathrm{X}$ is entirely generated by 70 external superconducting coils $[4,17]$, and large magnetic islands are naturally present in the edge. Among the 70 external coils, 50 non-planar coils form the toroidal and poloidal components of the main magnetic field, and 20 planar coils produce the vertical and toroidal components to vary the plasma shape. The rotational transform values ( 1 ) for each magnetic configuration depends on the current settings of the planar coils. Three major divertor configurations with edge iota values $\left(l_{\mathrm{a}}\right.$ ) of $5 / 6,5 / 5$ and $5 / 4$ have been chosen. The mirror ratio for each magnetic configuration is controlled by the current settings of the non-planar coils, and also affects the island positions. The predefined magnetic configurations include the standard configuration (edge iota $l_{\mathrm{a}}=5 / 5$, toroidal mirror term $\left.b_{01}=3 \%-4.5 \%\right)$, the high iota configuration $\left(l_{\mathrm{a}}=5 / 4\right.$, $\left.b_{01}=4.5 \%-5.5 \%\right)$, the low iota configuration $\left(l_{\mathrm{a}}=5 / 6, b_{01}=2.5 \%-3.5 \%\right)$, the high mirror configuration $\left(l_{\mathrm{a}}=5 / 5, b_{01}=10 \%\right)$, the low mirror configuration $\left(l_{\mathrm{a}}=5 / 5, b_{01}=0\right)$ and their derivatives $[18,19]$. The test divertor units are placed near the pre-calculated island O-points to open the closed field lines. During OP1.2a, the helium discharges were performed in between the hydrogen discharges as a wall conditioning method and also for commissioning operation scenarios. The plasmas were maintained solely by electron cyclotron resonance heating $(\mathrm{ECRH})$. The heating power for discharges showing in this study was in the range of 1-6 MW. The line-integrated electron density (unit: $\mathrm{m}^{-2}$ ) is measured by the single channel dispersion interferometer and the integral path is around $1 \mathrm{~m}$ long through the plasma. The line-integrated electron density was in the range of $(1-9.1) \times 10^{19} \mathrm{~m}^{-2}$ for the helium discharges and $(1-3.2) \times 10^{19} \mathrm{~m}^{-2}$ for the hydrogen discharges.

A compact overview spectroscopy system was installed on port AEI51 to monitor the fuel and impurity emissions in the divertor region. Figure 1 shows the schematic view of the overview spectroscopy system. The system views the divertor plasma through a pumping gap between the vertical and horizontal divertor targets. The field of view (FOV) is $10 \mathrm{~cm}$ in the vertical direction and $20 \mathrm{~cm}$ in the toroidal direction. In the same toroidal location, a gas inlet system is installed under the horizontal divertor targets for gas fuelling and impurity seeding $[20,21]$. The light from divertor plasmas is collected by $800 \mu \mathrm{m}$ core diameter optical fibers and then transferred to the spectroscopy room outside the torus hall. The overview spectrometer is a combined device with 5 small miniature spectrometers (Avantes model AVASPEC-ULS2048L). Each miniature spectrometer has a single input port with a standard SMA905 fiber adapter and different grating settings to cover a certain wavelength range. Together five channels can cover from $300 \mathrm{~nm}$ to $1100 \mathrm{~nm}$ and provide simultaneous measurements for hydrogen, helium, carbon, oxygen and other line emissions falling into this wavelength range. Each miniature spectrometer has a built-in CCD detector with $1 \times$ 2048 pixels. The reciprocal linear dispersion of the system is in the range of $0.04-0.19$ 


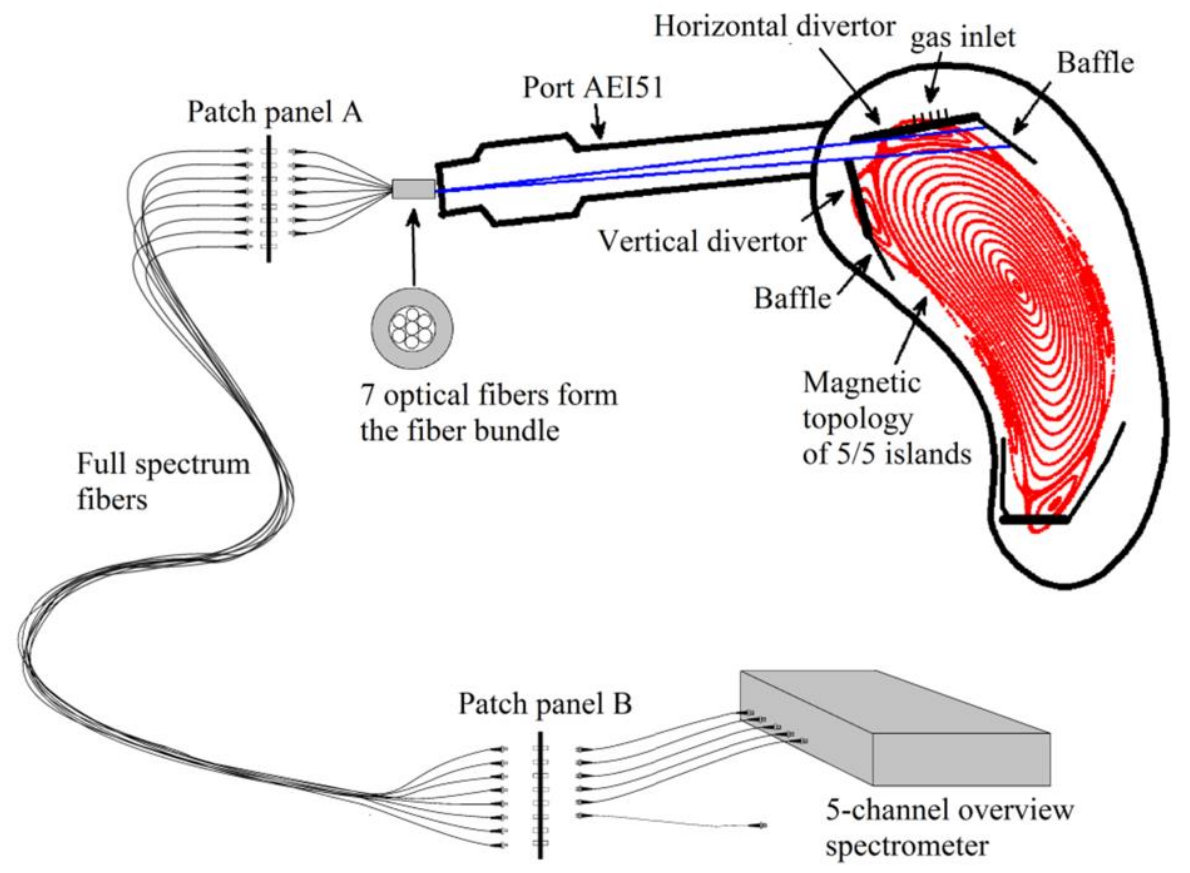

Figure 1. Schematic view of the overview spectroscopy system. The system views the upper divertor region through a pumping gap between the vertical and horizontal divertor. A gas inlet system is installed under the horizontal divertor. The plotted magnetic topology corresponds to the $5 / 5$ island chain. A fiber bundle of 7 optical fibers is installed outside the port AEI51 to collect the light from divertor plasmas, and then the light is carries by the full spectrum fibers to the 5-channel overview spectrometer located in the spectroscopy room.

$\mathrm{nm} /$ pixels, and the spectral resolution is in the range of $0.19-0.48 \mathrm{~nm}$ (defined as the full width at half maximum (FWHM) of a single peak). The system has a minimum integration time of $1.05 \mathrm{~ms}$. During OP1.2a, an optimal $10 \mathrm{~ms}$ integration time with good signal to noise ratio has been achieved.

\section{Experimental results and discussion}

\subsection{Spectral survey}

A spectral survey was completed with the absolute intensity calibrated overview spectroscopy system. Several characteristic spectral lines of hydrogen and helium were identified. The existence of carbon, oxygen and iron impurities in the plasmas due to plasmawall interaction was also confirmed by their characteristic spectral lines. Impurity seeding events with neon or nitrogen for radiative cooling were well captured.

Figure 2 shows the overview of a typical hydrogen discharge with neon seeding through the divertor gas inlet. The discharge was performed in reversed field standard configuration (with 5/5 island chain). 2.7 MW ECRH power was applied and the core electron temperature was maintained around $4.2 \mathrm{keV}$. The line-integrated electron density is shown in figure 2(b). The main gas valves were used for $\mathrm{H}_{2}$ gas fueling, and the divertor gas inlet was used for 
neon seeding from $3 \mathrm{~s}$ to $3.4 \mathrm{~s}$. Figures $2(\mathrm{~g})$ and $(\mathrm{h})$ show the spectrum before and during the neon seeding. The identified ions and transitions are shown in tables 1 and 2. The hydrogen Balmer lines $\mathrm{H}_{\alpha}$ and $\mathrm{H}_{\beta}$ were observed. The $\mathrm{H}_{\gamma}$ and $\mathrm{H}_{\delta}$ were usually very weak and overshadowed by nearby O II lines. The $\mathrm{H}_{\gamma}(434.0 \mathrm{~nm})$ was partially overlapped with the OII lines $(434.7 \mathrm{~nm}$ and $434.9 \mathrm{~nm})$, and the $\mathrm{H}_{\delta}(410.2 \mathrm{~nm})$ conjoined with the $\mathrm{O}$ II line (409.7 $\mathrm{nm})$. The $\mathrm{H}_{\alpha}$ line $(656.3 \mathrm{~nm})$ was chosen for monitoring the hydrogen fueling and recycling, and its time trace was shown in figure 2(c). Due to switching back and forth between the helium and hydrogen discharges, strong hydrogen emission was seen in the helium discharges, and strong helium emission in the hydrogen discharges as well. In some hydrogen discharges, helium beam was injected in divertor module 30 for diagnostic purpose, which also contributed to the helium emission in divertor module 51 due to transport inside the magnetic island. Multiple He I lines $(587.6 \mathrm{~nm}, 667.8 \mathrm{~nm}, 706.5 \mathrm{~nm}, 728.1 \mathrm{~nm}$ and $1083.0 \mathrm{~nm})$ and He II $(468.6 \mathrm{~nm})$ were identified. The He I line $(587.6 \mathrm{~nm})$ was selected to show the time trace of helium emission, as seen in figure 2(d). Carbon, oxygen and iron emissions were seen in every discharges recorded by the spectroscopy during OP1.2a. A series of C I-III, O I-II and Fe I lines are observed, indicating the existence of carbon, oxygen and iron impurities in the plasmas. The C II line $(514.5 \mathrm{~nm})$ and O I line $(777.2 \mathrm{~nm})$ were used to monitor the evolution of the carbon and oxygen emissions, as seen in figures 2 (e) and (f).
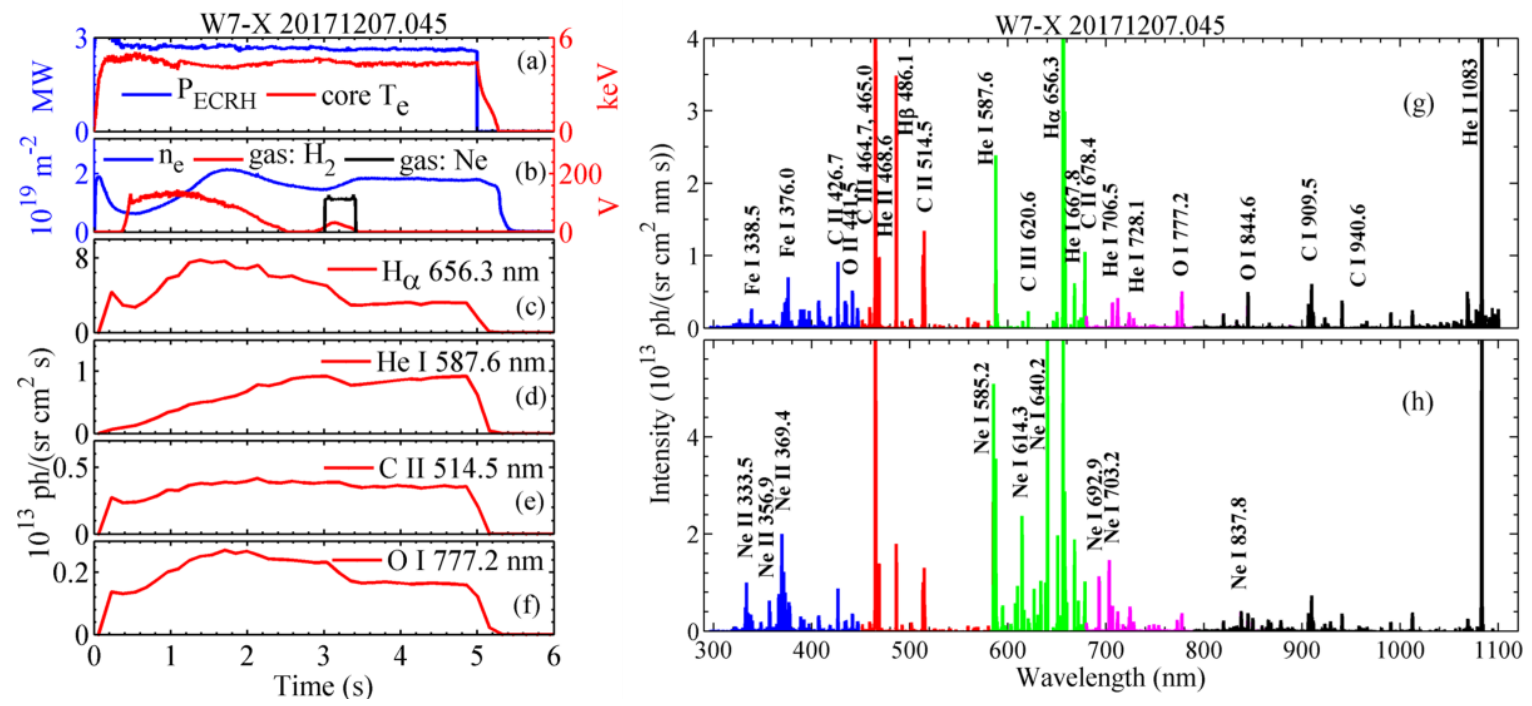

Figure 2. Overview of a typical hydrogen discharge with neon seeding through divertor gas inlet. The time traces in the left figure from top to bottom are (a) the ECRH heating power $\left(P_{\mathrm{ECRH}}\right)$, and the core electron temperature (core $T_{\mathrm{e}}$ ), (b) the line-integrated electron density $\left(n_{\mathrm{e}}\right.$ ), and the valve voltage of main gas fuelling system $\left(\mathrm{H}_{2}\right)$ and divertor gas inlet $(\mathrm{Ne})$, (c) the $\mathrm{H}_{\alpha}$ photon flux, (d) the He I photon flux, (e) the $\mathrm{C}$ II photon flux and (f) the O I photon flux. The spectra before and during neon seeding are plotted in the right figure $(\mathrm{g})$ and $(\mathrm{h})$ with spectral lines of $\mathrm{H}, \mathrm{He}, \mathrm{C}, \mathrm{O}, \mathrm{Fe}$ and $\mathrm{Ne}$ identified and labeled. 
Figure 3 shows a typical hydrogen discharge with nitrogen seeding through the divertor gas inlet. The nitrogen seeding happened at 3-3.32 s and 4.5-4.56 s. Figures 3(g) and (h) show the identified and labeled spectral lines before and during the nitrogen seeding. The identified nitrogen lines and transitions are listed in table 3. N I-IV lines were identified while only Ne I-II lines were seen in figure 2, despite the two discharges having very similar parameters. This is due to the fact that in the same ionization stage, nitrogen has lower ionization energy compared to neon. For instance, the ionization energy of N II is $29.60 \mathrm{eV}$, while the ionization energy of Ne II is $40.96 \mathrm{eV}$, according to the Atomic Data Analysis Structure (ADAS) database [22].
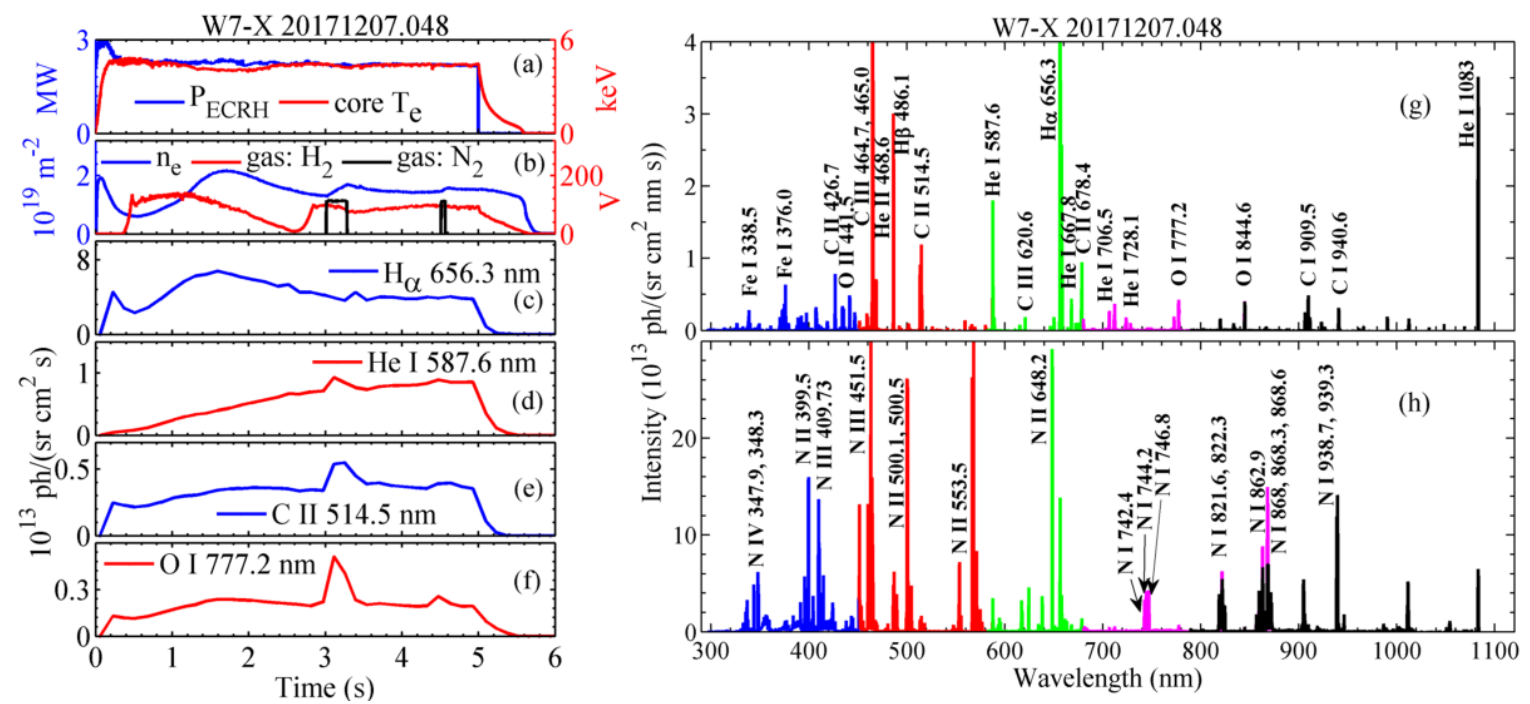

Figure 3. Overview of a typical hydrogen discharge with nitrogen seeding through the divertor gas inlet. The time traces in the left figure from top to bottom are (a) the ECRH heating power $\left(P_{\mathrm{ECRH}}\right)$, and the core electron temperature (core $T_{\mathrm{e}}$ ), (b) the line-integrated electron density $\left(n_{\mathrm{e}}\right)$, and the valve voltage of main gas fuelling system $\left(\mathrm{H}_{2}\right)$ and divertor gas inlet $\left(\mathrm{N}_{2}\right)$, (c) the $\mathrm{H}_{\alpha}$ photon flux, (d) the $\mathrm{He}$ I photon flux, (e) the $\mathrm{C}$ II photon flux and (f) the $\mathrm{O}$ I photon flux. The spectra before and during nitrogen seeding are plotted in the right figure (g) and (h) with spectral lines of $\mathrm{H}, \mathrm{He}, \mathrm{C}, \mathrm{O}, \mathrm{Fe}$ and $\mathrm{N}$ identified and labeled.

Table 1. List of identified spectral lines in W7-X plasmas

\begin{tabular}{lll}
\hline Type of line & Transition & Wavelength (nm) \\
\hline Fe I & $3 \mathrm{~d}^{6}\left({ }^{3} \mathrm{~F} 2\right) 4 \mathrm{~s} 4 \mathrm{p}\left({ }^{3} \mathrm{P}^{\circ}\right) \mathrm{x}^{3} \mathrm{~F}^{\circ} \rightarrow 3 \mathrm{~d}^{7}\left({ }^{4} \mathrm{P}\right) 4 \mathrm{~s} \mathrm{a}{ }^{5} \mathrm{P}$ & 338.5 \\
Fe I & $3 \mathrm{~d}^{6}\left({ }^{3} \mathrm{H}\right) 4 \mathrm{~s} 4 \mathrm{p}\left({ }^{3} \mathrm{P}^{\circ}\right) \mathrm{z}^{3} \mathrm{I}^{\circ} \rightarrow 3 \mathrm{~d}^{6} 4 \mathrm{~s}^{2} \mathrm{a}{ }^{3} \mathrm{H}$ & 376.0 \\
C II & $2 \mathrm{~s}^{2} 4 \mathrm{f}^{2} \mathrm{~F}^{\circ} \rightarrow 2 \mathrm{~s}^{2} 3 \mathrm{~d}^{2} \mathrm{D}$ & 426.7 \\
O II & $2 \mathrm{~s}^{2} 2 \mathrm{p}^{2}\left({ }^{3} \mathrm{P}\right) 3 \mathrm{p}^{2} \mathrm{D}^{\circ} \rightarrow 2 \mathrm{~s}^{2} 2 \mathrm{p}^{2}\left({ }^{3} \mathrm{P}\right) 3 \mathrm{~s}^{2} \mathrm{P}$ & 441.5 \\
C III & $1 \mathrm{~s}^{2} 2 \mathrm{~s} 3 \mathrm{p}^{3} \mathrm{P}^{\circ} \rightarrow 1 \mathrm{~s}^{2} 2 \mathrm{~s} 3 \mathrm{~s}^{3} \mathrm{~S}$ & $464.7,465.0$ \\
He II & $4 \rightarrow 3$ & 468.6 \\
H I (Balmer- $\beta)$ & $4 \rightarrow 2$ & 486.1 \\
C II & $2 \mathrm{~s} 2 \mathrm{p}\left({ }^{3}{ }^{\circ}\right) 3 \mathrm{p}{ }^{4} \mathrm{P} \rightarrow 2 \mathrm{~s} 2 \mathrm{p}\left({ }^{3} \mathrm{P}^{\circ}\right) 3 \mathrm{~s}{ }^{4} \mathrm{P}^{\circ}$ & 514.5 \\
He I & $1 \mathrm{~s} 3 \mathrm{~d}^{3} \mathrm{D} \rightarrow 1 \mathrm{~s} 2 \mathrm{p}^{3} \mathrm{P}^{\circ}$ & 587.6 \\
C III & $1 \mathrm{~s}^{2} 2 \mathrm{~s} 5 \mathrm{~s}{ }^{1} \mathrm{~S} \rightarrow 1 \mathrm{~s}^{2} 2 \mathrm{~s} 4 \mathrm{p}^{1} \mathrm{P}^{\circ}$ & 620.6 \\
H I $($ Balmer- $\alpha)$ & $3 \rightarrow 2$ & 656.3 \\
He I & $1 \mathrm{~s} 3 \mathrm{~d}{ }^{1} \mathrm{D} \rightarrow 1 \mathrm{~s} 2 \mathrm{p}{ }^{1} \mathrm{P}^{\circ}$ & 667.8
\end{tabular}




\begin{tabular}{|c|c|c|}
\hline C II & $2 \mathrm{~s} 2 \mathrm{p}\left({ }^{3} \mathrm{P}^{\circ}\right) 3 \mathrm{p}{ }^{4} \mathrm{D} \rightarrow 2 \mathrm{~s} 2 \mathrm{p}\left({ }^{3} \mathrm{P}^{\circ}\right) 3 \mathrm{~s}{ }^{4} \mathrm{P}^{\circ}$ & 678.4 \\
\hline $\mathrm{He} \mathrm{I}$ & $1 \mathrm{~s} 3 \mathrm{~s}^{3} \mathrm{~S} \rightarrow 1 \mathrm{~s} 2 \mathrm{p}{ }^{3} \mathrm{P}^{\circ}$ & 706.5 \\
\hline $\mathrm{He} \mathrm{I}$ & $1 \mathrm{~s} 3 \mathrm{~s}{ }^{1} \mathrm{~S} \rightarrow 1 \mathrm{~s} 2 \mathrm{p}{ }^{1} \mathrm{P}^{\circ}$ & 728.1 \\
\hline O I & $2 s^{2} 2 p^{3}\left({ }^{4} S^{\circ}\right) 3 p^{5} P \rightarrow 2 s^{2} 2 p^{3}\left({ }^{4} S^{\circ}\right) 3 s^{5} S^{\circ}$ & 777.2 \\
\hline O I & $2 s^{2} 2 p^{3}\left({ }^{4} S^{\circ}\right) 3 p{ }^{3} P \rightarrow 2 s^{2} 2 p^{3}\left({ }^{4} S^{\circ}\right) 3 s^{3} S^{\circ}$ & 844.6 \\
\hline C I & $2 \mathrm{~s}^{2} 2 \mathrm{p} 3 \mathrm{p}^{3} \mathrm{P} \rightarrow 2 \mathrm{~s}^{2} 2 \mathrm{p} 3 \mathrm{~s}^{3} \mathrm{P}^{\circ}$ & 909.5 \\
\hline $\mathrm{C} \mathrm{I}$ & $2 \mathrm{~s}^{2} 2 \mathrm{p} 3 \mathrm{p}^{1} \mathrm{D} \rightarrow 2 \mathrm{~s}^{2} 2 \mathrm{p} 3 \mathrm{~s}^{1} \mathrm{P}^{\circ}$ & 940.6 \\
\hline $\mathrm{He} \mathrm{I}$ & $1 \mathrm{~s} 2 \mathrm{p}^{3} \mathrm{P}^{\circ} \rightarrow 1 \mathrm{~s} 2 \mathrm{~s}{ }^{3} \mathrm{~S}$ & 1083.0 \\
\hline Type of line & Transition & Wavelength (nm) \\
\hline $\mathrm{Ne}$ II & $2 s^{2} 2 p^{4}\left({ }^{3} P\right) 3 p{ }^{4} D^{\circ} \rightarrow 2 s^{2} 2 p^{4}\left({ }^{3} P\right) 3 s{ }^{4} P$ & 333.5 \\
\hline $\mathrm{Ne}$ II & $2 s^{2} 2 p^{4}\left({ }^{3} \mathrm{P}\right) 3 \mathrm{p}^{4} \mathrm{P}^{\circ} \rightarrow 2 \mathrm{~s}^{2} 2 \mathrm{p}^{4}\left({ }^{3} \mathrm{P}\right) 3 \mathrm{~s}{ }^{4} \mathrm{P}$ & 369.4 \\
\hline $\mathrm{Ne} I$ & $2 \mathrm{~s}^{2} 2 \mathrm{p}^{5}\left({ }^{2} \mathrm{P}_{1 / 2}^{\circ}\right) 3 \mathrm{p}^{2}[1 / 2] \rightarrow 2 \mathrm{~s}^{2} 2 \mathrm{p}^{5}\left({ }^{2} \mathrm{P}^{\circ}{ }_{1 / 2}\right) 3 \mathrm{~s}^{2}[1 / 2]^{\circ}$ & 585.2 \\
\hline $\mathrm{Ne} I$ & $2 \mathrm{~s}^{2} 2 \mathrm{p}^{5}\left({ }^{2} \mathrm{P}_{3 / 2}^{\circ}\right) 3 \mathrm{p}^{2}[3 / 2] \rightarrow 2 \mathrm{~s}^{2} 2 \mathrm{p}^{5}\left({ }^{2} \mathrm{P}_{3 / 2}^{\circ}\right) 3 \mathrm{~s}^{2}[3 / 2]^{\circ}$ & 614.3 \\
\hline $\mathrm{Ne} I$ & $2 \mathrm{~s}^{2} 2 \mathrm{p}^{5}\left({ }^{2} \mathrm{P}_{3 / 2}^{\circ}\right) 3 \mathrm{p}^{2}[5 / 2] \rightarrow 2 \mathrm{~s}^{2} 2 \mathrm{p}^{5}\left({ }^{2} \mathrm{P}_{3 / 2}^{\circ}\right) 3 \mathrm{~s}^{2}[3 / 2]^{\circ}$ & 640.2 \\
\hline $\mathrm{Ne} I$ & $2 \mathrm{~s}^{2} 2 \mathrm{p}^{5}\left({ }^{2} \mathrm{P}_{3 / 2}^{\circ}\right) 3 \mathrm{p}^{2}[3 / 2] \rightarrow 2 \mathrm{~s}^{2} 2 \mathrm{p}^{5}\left({ }^{2} \mathrm{P}^{\circ}{ }_{1 / 2}\right) 3 \mathrm{~s}^{2}[1 / 2]^{\circ}$ & 692.9 \\
\hline $\mathrm{Ne} I$ & $2 \mathrm{~s}^{2} 2 \mathrm{p}^{5}\left({ }^{2} \mathrm{P}_{3 / 2}^{\circ}\right) 3 \mathrm{p}^{2}[1 / 2] \rightarrow 2 \mathrm{~s}^{2} 2 \mathrm{p}^{5}\left({ }^{2} \mathrm{P}_{3 / 2}^{\circ}\right) 3 \mathrm{~s}^{2}[3 / 2]^{\circ}$ & 703.2 \\
\hline $\mathrm{Ne} I$ & $2 \mathrm{~s}^{2} 2 \mathrm{p}^{5}\left({ }^{2} \mathrm{P}_{3 / 2}^{\circ}\right) 3 \mathrm{~d}^{2}[7 / 2]^{\circ} \rightarrow 2 \mathrm{~s}^{2} 2 \mathrm{p}^{5}\left({ }^{2} \mathrm{P}_{3 / 2}^{\circ}\right) 3 \mathrm{p}^{2}[5 / 2]$ & 837.8 \\
\hline
\end{tabular}

Table 3. List of identified nitrogen lines in W7-X plasmas during nitrogen seeding

\begin{tabular}{lll}
\hline Type of line & Transition & Wavelength $(\mathrm{nm})$ \\
\hline N IV & $1 \mathrm{~s}^{2} 2 \mathrm{~s} 3 \mathrm{p}^{3} \mathrm{P}^{\circ} \rightarrow 1 \mathrm{~s}^{2} 2 \mathrm{~s} 3 \mathrm{~s}^{3} \mathrm{~S}$ & $347.9,348.3$ \\
N II & $2 \mathrm{~s}^{2} 2 \mathrm{p} 3 \mathrm{p}{ }^{1} \mathrm{D} \rightarrow 2 \mathrm{~s}^{2} 2 \mathrm{p} 3 \mathrm{~s}^{1} \mathrm{P}^{\circ}$ & 399.5 \\
N III & $2 \mathrm{~s}^{2} 3 \mathrm{p}^{2} \mathrm{P}^{\circ} \rightarrow 2 \mathrm{~s}^{2} 3 \mathrm{~s}^{2} \mathrm{~S}$ & 409.7 \\
N III & $2 \mathrm{~s} 2 \mathrm{p}\left({ }^{3} \mathrm{P}^{\circ}\right) 3 \mathrm{p}{ }^{4} \mathrm{D} \rightarrow 2 \mathrm{~s} 2 \mathrm{p}\left({ }^{3} \mathrm{P}^{\circ}\right) 3 \mathrm{~s}{ }^{4} \mathrm{P}^{\circ}$ & 451.5 \\
N II & $2 \mathrm{~s}^{2} 2 \mathrm{p} 3 \mathrm{~d}^{3} \mathrm{~F}^{\circ} \rightarrow 2 \mathrm{~s}^{2} 2 \mathrm{p} 3 \mathrm{p}{ }^{3} \mathrm{D}$ & $500.1,500.5$ \\
N II & $2 \mathrm{~s}^{2} \mathrm{p}^{2}\left({ }^{4} \mathrm{P}\right) 3 \mathrm{p}^{5} \mathrm{D}^{\circ} \rightarrow 2 \mathrm{~s}^{2} \mathrm{p}^{2}\left({ }^{4} \mathrm{P}\right) 3 \mathrm{~s}{ }^{5} \mathrm{P}$ & 553.5 \\
N II & $2 \mathrm{~s}^{2} 2 \mathrm{p} 3 \mathrm{p}{ }^{1} \mathrm{P} \rightarrow 2 \mathrm{~s}^{2} 2 \mathrm{p} 3 \mathrm{~s}^{1} \mathrm{P}^{\circ}$ & 648.2 \\
N I & $2 \mathrm{~s}^{2} 2 \mathrm{p}^{2}\left({ }^{3} \mathrm{P}\right) 3 \mathrm{p}^{4} \mathrm{~S}^{\circ} \rightarrow 2 \mathrm{~s}^{2} 2 \mathrm{p}^{2}\left({ }^{3} \mathrm{P}\right) 3 \mathrm{~s}{ }^{4} \mathrm{P}$ & $742.4,744.2,746.8$ \\
N I & $2 \mathrm{~s}^{2} 2 \mathrm{p}^{2}\left({ }^{3} \mathrm{P}\right) 3 \mathrm{p}{ }^{4} \mathrm{P}^{\circ} \rightarrow 2 \mathrm{~s}^{2} 2 \mathrm{p}^{2}\left({ }^{3} \mathrm{P}\right) 3 \mathrm{~s}^{4} \mathrm{P}$ & $821.6,822.3$ \\
N I & $2 \mathrm{~s}^{2} 2 \mathrm{p}^{2}\left({ }^{3} \mathrm{P}\right) 3 \mathrm{p}{ }^{2} \mathrm{P}^{\circ} \rightarrow 2 \mathrm{~s}^{2} 2 \mathrm{p}^{2}\left({ }^{3} \mathrm{P}\right) 3 \mathrm{~s}{ }^{2} \mathrm{P}$ & 862.9 \\
N I & $2 \mathrm{~s}^{2} 2 \mathrm{p}^{2}\left({ }^{3} \mathrm{P}\right) 3 \mathrm{p}{ }^{4} \mathrm{D}^{\circ} \rightarrow 2 \mathrm{~s}^{2} 2 \mathrm{p}^{2}\left({ }^{3} \mathrm{P}\right) 3 \mathrm{~s}{ }^{4} \mathrm{P}$ & $868.0,868.3,868.6$ \\
N I & $2 \mathrm{~s}^{2} 2 \mathrm{p}^{2}\left({ }^{3} \mathrm{P}\right) 3 \mathrm{p}^{2} \mathrm{D}^{\circ} \rightarrow 2 \mathrm{~s}^{2} 2 \mathrm{p}^{2}\left({ }^{3} \mathrm{P}\right) 3 \mathrm{~s}{ }^{2} \mathrm{P}$ & $938.7,939.3$ \\
\hline
\end{tabular}

\subsection{Divertor electron temperature and density measured by $\mathrm{He} \mathrm{I}$ line intensity ratios}

The He I line ratio method is widely used in fusion devices to measure the electron temperature $\left(T_{\mathrm{e}}\right)$ and density $\left(n_{\mathrm{e}}\right)$ in the plasma edge. The line intensity ratio between $\mathrm{He} \mathrm{I}$ $728.1 \mathrm{~nm}$ and He I $706.5 \mathrm{~nm}$ is insensitive to $n_{\mathrm{e}}$ variation, and therefore can be used for $T_{\mathrm{e}}$ determination. In contrast, the line intensity ratio between He I $728.1 \mathrm{~nm}$ and $\mathrm{He}$ I $667.8 \mathrm{~nm}$ is insensitive to $T_{\mathrm{e}}$ variation and can be used for $n_{\mathrm{e}}$ measurement [23-25]. The intensities of the three mentioned He I lines are simultaneously measured by the overview spectroscopy system. The expressions obtained from the collisional-radiative mode (CRM) by de la Cal 
$[26,27]$ are adopted in the study to preliminarily estimate the divertor $T_{\mathrm{e}}$ and $n_{\mathrm{e}}$ from the measured He I line ratios. On experimental day $5^{\text {th }}$ of December 2017, a series of continuous helium discharges were performed. The divertor $T_{\mathrm{e}}$ and $n_{\mathrm{e}}$ derived from spectral data are compared with the Langmuir probe data, as shown in figure 4. There are ten Langmuir probe pins radially locate on the horizontal divertor panel of module 51, with PIN 1 nearest to the pumping gap. The data from PIN 3, 6 and 9 are used for comparison, as seen in figures 4(c) and (d). The $n_{\mathrm{e}}$ from spectral data is an order of magnitude higher than the probe data; however the qualitative trend of the $n_{\mathrm{e}}$ evaluated from the spectral data is very similar to that of the $n_{\mathrm{e}}$ obtained with the probe. By comparing to the line-integrated $n_{\mathrm{e}}$, the divertor $n_{\mathrm{e}}$ shows the same trend as the line-integrated $n_{\mathrm{e}}$, as seen in figure 4(b) and (d). Investigation over 76 helium discharges and 40 hydrogen discharges showed that the divertor $n_{\mathrm{e}}$ increases with increasing line-integrated $n_{\mathrm{e}}$ while show little dependence on ECRH power, as seen in figure 5 . The increase of divertor $n_{\mathrm{e}}$ with the line-integrated $n_{\mathrm{e}}$ shows two different trends. A quick increase in divertor $n_{\mathrm{e}}$ can be seen when line-integrated $n_{\mathrm{e}}$ is below $4 \times 10^{19} \mathrm{~m}^{-2}$. Then the increase of divertor $n_{\mathrm{e}}$ becomes slower when line-integrated $n_{\mathrm{e}}$ is over $4 \times 10^{19} \mathrm{~m}^{-2}$. The divertor $T_{\mathrm{e}}$, while for most discharges, it follows the trend of ECRH power, is also influenced by the local electron density. As shown in figures 4(a) and (c), discharges 20171205.20-22 have same heating power as 2.8 MW while the line-integrated $n_{\mathrm{e}}$ increases linearly from $3.5 \times 10^{19} \mathrm{~m}^{-2}$ to $6.5 \times 10^{19} \mathrm{~m}^{-2}$, the divertor $T_{\mathrm{e}}$ decreases from $23 \mathrm{eV}$ to $17 \mathrm{eV}$ according to the spectral data.

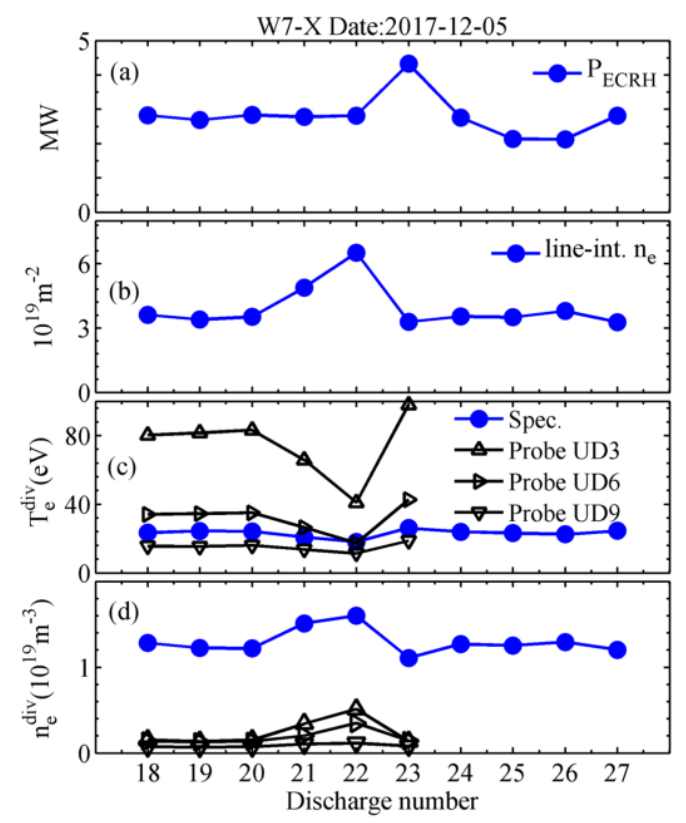

Figure 4. The ECRH heating power (a), line-integrated electron density (b), electron temperature from divertor spectroscopy and divertor Langmuir probes (c), and electron density from divertor spectroscopy and divertor Langmuir probes (d) of a series of helium discharges. The data points for each discharge were obtained by averaging over a central phase of $1 \mathrm{~s}$ in the ECRH power flat-top phase without fueling or impurity seeding. 


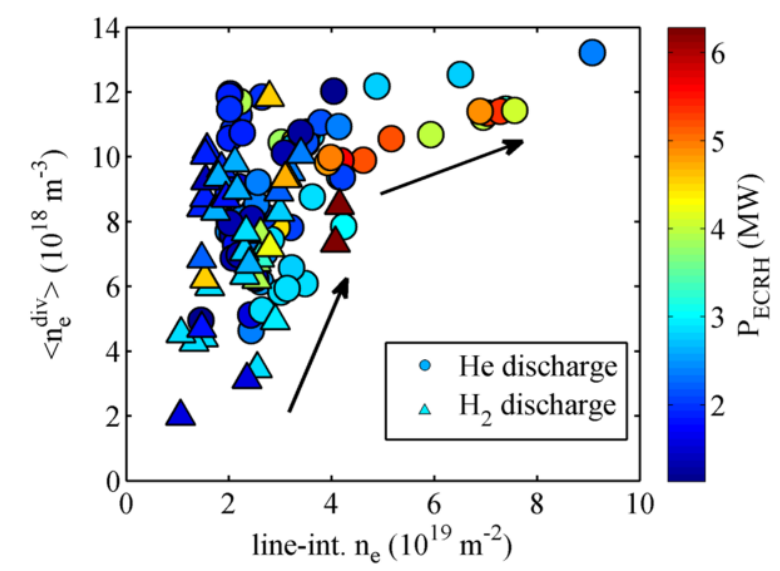

Figure 5. The divertor electron density increases with increasing line-integrated electron density, while shows little dependence on ECRH power.

\subsection{Comparison between hydrogen discharges and helium discharges}

During OP1.2a, helium discharges were frequently performed between hydrogen discharges. Two discharges under the reversed standard configuration were compared to show the difference of divertor emissions in typical helium discharge and hydrogen discharge, as seen in figure 6. The two discharges have similar heating power and pulse length while the helium discharges have higher electron density, as shown in figures 6(a) and (b). Figures 6(c) and (d) show the divertor $T_{\mathrm{e}}$ and $n_{\mathrm{e}}$. The helium discharge has higher divertor $n_{\mathrm{e}}$ than the hydrogen discharge, the same as the line-integrated $n_{\mathrm{e}}$. In the hydrogen discharge, neon was seeded through the divertor gas inlet from $3 \mathrm{~s}$ to $3.4 \mathrm{~s}$. After neon injection, the divertor $T_{\mathrm{e}}$ shows a drop of $23 \%$ and the divertor $n_{\mathrm{e}}$ shows a raise of $45 \%$. The missing of data points of divertor $n_{\mathrm{e}}$ around $3 \mathrm{~s}$ and the dash lined data points after $3.5 \mathrm{~s}$ is due to the contamination of neon to helium line measurement. The He I line $(667.815 \mathrm{~nm})$ used for $n_{\mathrm{e}}$ measurement is contaminated by a Ne I line $(667.828 \mathrm{~nm})$. The neon seeding causes strong Ne I-II emissions, and after neon injection, the Ne emissions drop but remain at a low level in the plasma due to high recycling. The time evolution of $\mathrm{Ne} I(640.2 \mathrm{~nm})$ line intensity confirmed that the Ne I line intensity drops to $20 \%$ at $3.5 \mathrm{~s}$ and remains $15 \%$ at the end of discharge (4.9 s). By assuming the $667.828 \mathrm{~nm} \mathrm{Ne} I$ line intensity has the same time evolution as $640.2 \mathrm{~nm}$ Ne I line intensity, we concluded that the divertor $n_{\mathrm{e}}$ from $3.5 \mathrm{~s}$ was overestimated by $10 \%-15 \%$. Figures $6(\mathrm{e})$ and (h) show the comparison of $\mathrm{H}_{\alpha}, \mathrm{He}$ I, C II and $\mathrm{O}$ I photon fluxes. In hydrogen discharge, the $\mathrm{H}_{\alpha}, \mathrm{C}$ II and $\mathrm{O}$ I emission were sensitive to the electron density change, while He I emission slowly raised over time. The main helium source in the hydrogen discharges is the helium neutrals dissolved from the first wall. In some cases, for example in the two discharges shown in figures 2 and 3, helium injection was performed at divertor module 30 (M30), which also contributed the helium emission at divertor module 51 (M51). In typical helium discharge, the $\mathrm{H}_{\alpha}$ emission is strongly depended 
on the ECRH power. The He I emission increases strongly with increasing $n_{\mathrm{e}}$ due to the helium gas fuelling. The C II emission in helium discharge is in the same level as the C II emission in hydrogen discharge, while the $\mathrm{O}$ I emission is much lower in the helium discharge. The carbon and oxygen levels in plasmas are influenced by not only working gas type but also magnetic topology and plasma conditions, which are analyzed in the following sections.

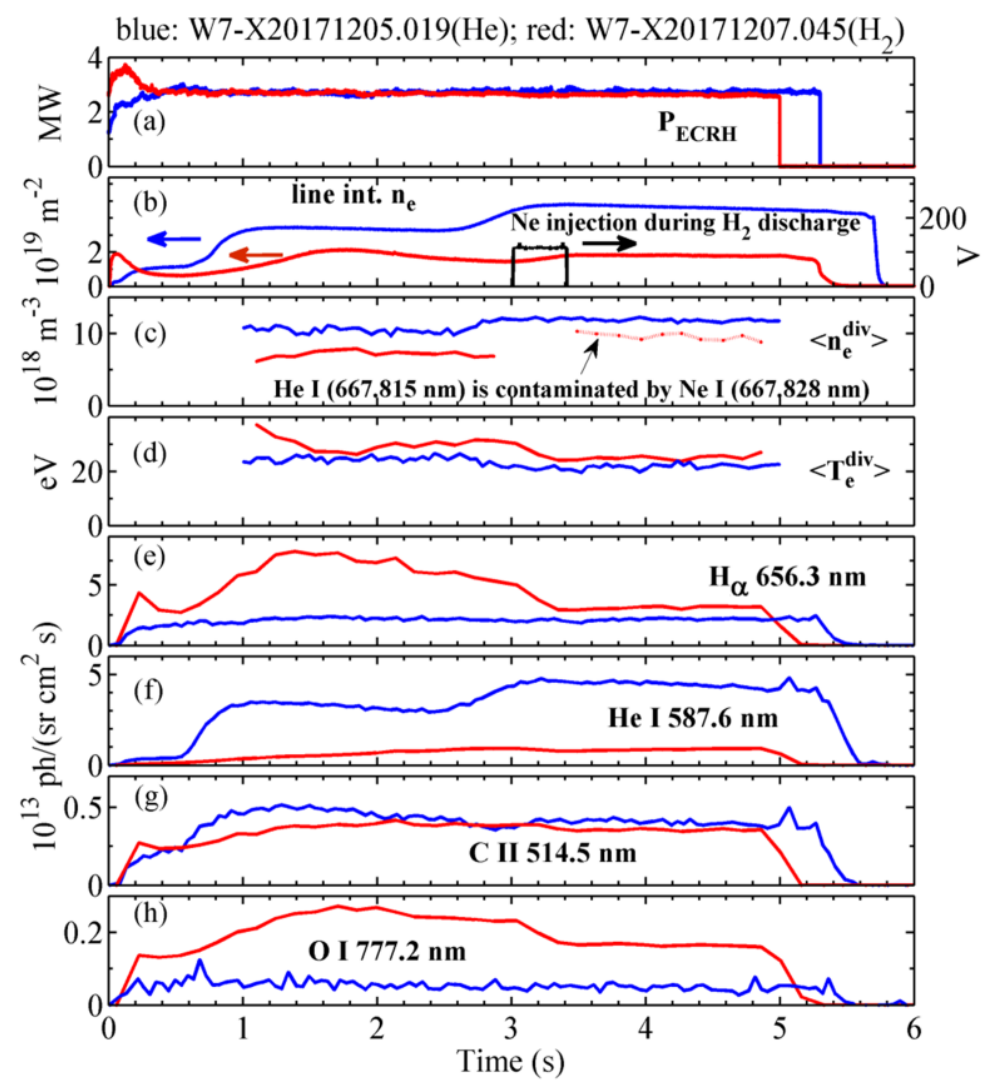

Figure 6. Comparison of a helium discharge (blue lines) and a hydrogen discharge (red lines). Time traces of (a) the ECRH heating power $\left(P_{\mathrm{ECRH}}\right)$, (b) the line-integrated electron density $\left(n_{\mathrm{e}}\right)$ and the valve voltage of the divertor gas inlet ( $\mathrm{Ne})$ in $\mathrm{H}_{2}$ discharge, (c) the divertor electron density $\left(\left\langle n_{\mathrm{e}}^{\text {div }}\right\rangle\right)$, (d) the divertor electron temperature $\left(\left\langle T_{\mathrm{e}}^{\mathrm{div}}\right\rangle\right.$ ), (e) the $\mathrm{H}_{\alpha}$ photon flux, (f) the He I photon flux, (g) the $\mathrm{C}$ II photon flux and (h) the O I photon flux.

\subsection{The influence of magnetic configurations on divertor emissions}

During OP1.2a, several magnetic configurations were commissioned. Listed in table 4 are the magnetic configurations which are investigated in this section. The W7-X magnet system can be divided into five identical modules, corresponding to 5 field periods. Due to the periodicity and the stellarator symmetry inside each period, only 5 non-planar coil currents (I1, I2, I3, I4 and I5) and 2 planar coil currents (IA and IB) of half a period are free for variations. By changing the current settings, different magnetic configurations can be achieved. A field line tracing (FLT) code has been applied to get the magnetic topology with 
Table 4. Magnetic field configuration settings

\begin{tabular}{|c|c|c|c|c|c|c|c|c|}
\hline \multirow{2}{*}{ Configuration } & \multicolumn{4}{|c|}{ Non-planar coil currents (A) } & \multicolumn{2}{|c|}{$\begin{array}{c}\text { Planar coil currents } \\
\text { (A) }\end{array}$} & \multirow{2}{*}{$\begin{array}{l}\text { Island } \\
\text { chain }\end{array}$} \\
\cline { 2 - 9 } & I1 & I2 & I3 & I4 & I5 & IA & IB & \\
\hline Standard & 13068 & 13068 & 13068 & 13068 & 13068 & -700 & -700 & $5 / 5$ \\
\hline High mirror & 13282 & 13007 & 12392 & 11776 & 11403 & -700 & -700 & $5 / 5$ \\
\hline High iota & 14188 & 14188 & 14188 & 14188 & 14188 & -9790 & -9790 & $5 / 4$ \\
\hline
\end{tabular}

given coil currents [28]. Figure 7 shows the Poincare plots of the standard configuration, the high mirror configuration and the high iota configuration in the toroidal section of the overview spectrometer. In order to give a full picture of the magnetic topology, the plasma facing components were not considered during this field line tracing. The standard magnetic configuration has a chain of 5 independent magnetic islands naturally present in the plasma edge. The divertor units are 3D-shaped to cut the islands open in certain locations, which is different for each configuration. The viewing geometry of the overview spectrometer is made that the island below the upper horizontal divertor is fully covered in the standard configuration. The high mirror configuration, as its name suggests, has a higher mirror ratio compared to the standard configuration. In the high mirror configuration, the 5/5 magnetic island chain is still present in the plasma edge, but the plasma shape slightly changes. Inside the spectrometer field of view (FOV), the island position moves downward. In the high iota configuration, a single island is helically winding around the confined plasma region thereby showing up in any poloidal cross section at 4 locations, as seen in figure 7(c). In this configuration, the strike lines are located at the toroidal far end of the top divertor, which for the lower divertor can be seen at the bottom of figure 4(c). This part of divertor target section is commonly referred to as the "high iota tail". In the high iota configuration, there is no strike line anywhere near the location of the FOV of the overview spectrometer.
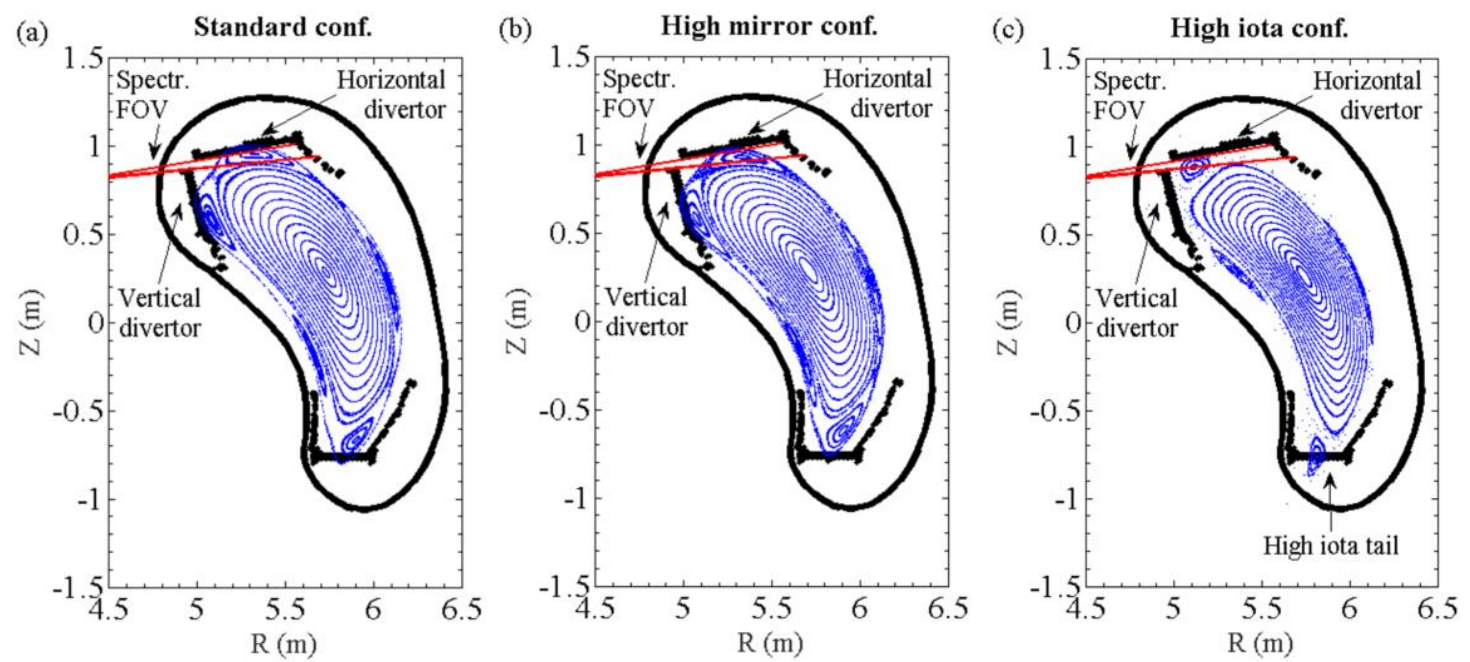

Figure 7. Poincaré plots for (a) the standard configuration, (b) the high mirror configuration and (c) the high iota configuration in the toroidal section of the UV-VIS-NIR overview spectrometer. The red lines indicate the field of view (FOV) of the overview spectrometer. 
The spectroscopic measurement shows a strong change of the emission levels in different magnetic configurations. Lower emission levels are seen in the high mirror and the high iota case. In figure 8, comparisons are made among three helium discharges in standard, high mirror and high iota configuration, respectively. As shown in figures 8(a) and (b), these three discharges have similar heating power of around 2.6 MW and line-integrated electron density of around $3 \times 10^{19} \mathrm{~m}^{-2}$. The divertor $n_{\mathrm{e}}$ and $T_{\mathrm{e}}$ derived from He I line ratios are shown in figures $8(\mathrm{c})$ and (d). These three discharges have similar divertor $n_{\mathrm{e}}$ around $7 \times 10^{18} \mathrm{~m}^{-3}$ and divertor $T_{\mathrm{e}}$ around $25 \mathrm{eV}$. The $\mathrm{H}_{\alpha}(\lambda=656.3 \mathrm{~nm}), \mathrm{He} \mathrm{I}(\lambda=587.6 \mathrm{~nm}), \mathrm{C}$ II $(\lambda=514.5 \mathrm{~nm})$ and $\mathrm{O} I(\lambda=777.2 \mathrm{~nm})$ photon fluxes are used to make the comparison between different magnetic configuration, as shown in figures $8(\mathrm{e})-(\mathrm{h})$. Going from standard to high mirror, to high iota configuration, the observed intensities of $\mathrm{H}_{\alpha}$, He I, C II and O I are lower and lower. Survey over helium and hydrogen discharges shows that the divertor plasma emissions exhibit a strong dependence on magnetic topology. The levels for $\mathrm{H}_{\alpha}, \mathrm{He}$ I, C II and O I emissions are all reduced moving from the standard configuration to the high mirror configuration, and even further reduced for the high iota configuration.

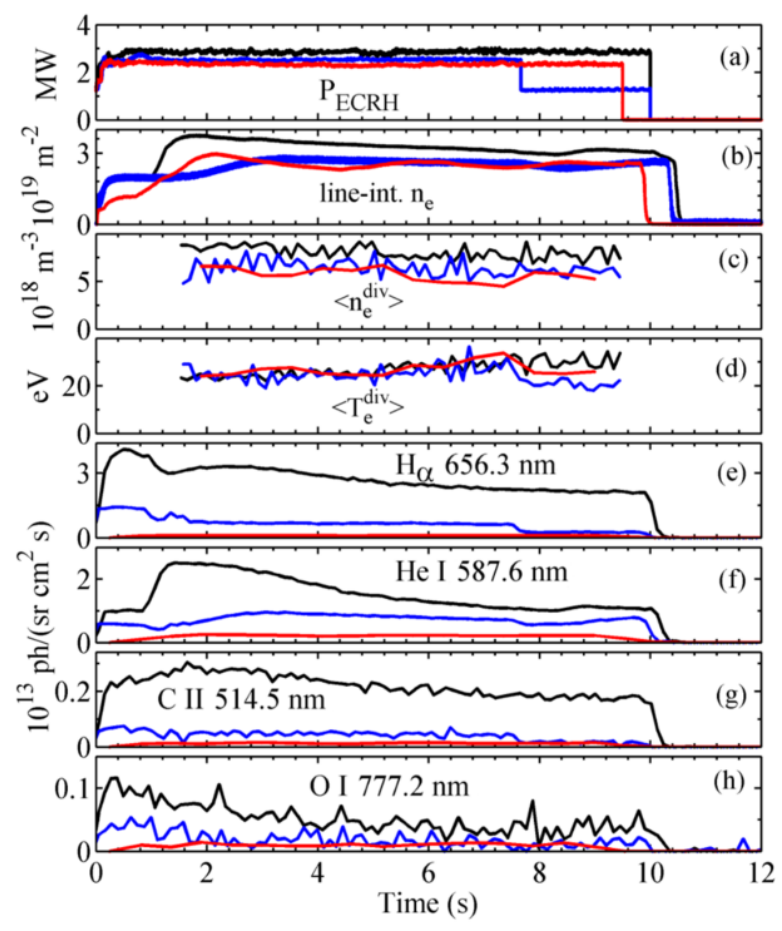

Figure 8. Time traces of (a) the ECRH heating power $\left(P_{\mathrm{ECRH}}\right)$, (b) the line-integrated electron density $\left(n_{\mathrm{e}}\right)$, (c) the divertor electron density $\left(\left\langle n_{\mathrm{e}}^{\text {div }}\right\rangle\right)$, (d) the divertor electron temperature $\left(\left\langle T_{\mathrm{e}}^{\text {div }}\right\rangle\right)$, (e) the $\mathrm{H}_{\alpha}$ photon flux, (f) the He I photon flux, (g) the C II photon flux and (h) the O I photon flux of three helium discharges in the standard configuration (black, W7-X20171114.043), the high mirror configuration (blue, W7-X20171122.011) and the high iota configuration (red, W7-X20171123.016), respectively. 
The difference in emission levels could be explained by the different magnetic topology. Figures 9(a)-(c) show the connection lengths of the standard configuration, the high mirror configuration and the high iota configuration at the top divertor region, respectively. The calculation was carried out using the field line tracing tool. The tracing started from the toroidal location of the overview spectroscopy system and was done both forwards and backwards direction with an upper limit of $300 \mathrm{~m}$ to mark the confined region. All plasma facing components including ten test divertor units were considered during the tracing for the connection length. As shown in figure 9(a), the view of the spectrometer covers the whole island near horizontal divertor in the standard configuration. When changing to the high mirror configuration, the confined region of the island reduces significantly, and the field lines near horizontal divertor are partially blocked by components in other toroidal sections due to the toroidal asymmetry of W7-X magnetic field. As for the high iota configuration, the strike lines completely move away from the observation zone of the overview spectrometer, causes the overview spectrometer mainly monitors the edge scrapeoff layer with much shorter connection lengths.
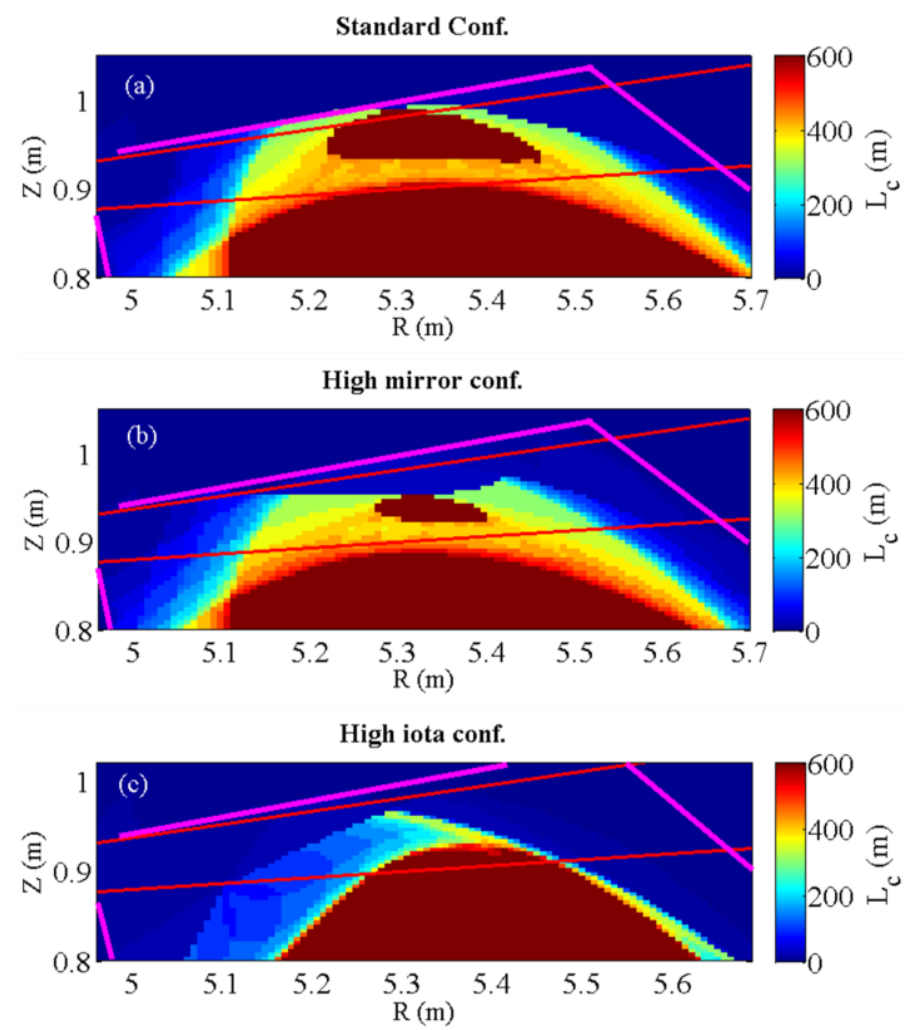

Figure 9. The connection lengths calculated for (a) the standard configuration, (b) the high mirror configuration and (c) the high iota configuration in the upper divertor region. The red lines indicate the FOV of the overview spectrometer. The pink lines indicate the locations of divertor components in this toroidal section. 


\subsection{Long time evolutions of divertor emissions}

In order to study the impurity evolutions, the ionizations per photon $(\mathrm{S} / \mathrm{XB})$ were obtained from ADAS [22] with the divertor electron temperature and density calculated from helium line ratios as input. By multiplying the $\mathrm{S} / \mathrm{XB}$ factors with the measured photon fluxes, the particle fluxes can be calculated [29].

Due to the mixture of hydrogen and helium in the plasmas, the particle flux ratio of $\mathrm{H}_{\alpha}$ and $\mathrm{He} \mathrm{I}$ is used as an indicator of fuel recycling [30]. Figure 10 shows the particle flux ratio $\mathrm{He} \mathrm{I} /\left(\mathrm{H}_{\alpha}+\mathrm{He} \mathrm{I}\right)$ over experimental days for both the hydrogen and the helium discharges. The data cover the experimental days from $14^{\text {th }}$ of November to $7^{\text {th }}$ of December. During this time period, the magnetic configuration was changed from the standard to high mirror and then to the high iota configuration. On $29^{\text {th }}$ of November, the bootstrap mimic configuration was commissioned to investigate the predicted heat flux overload. On the last experiment week, from $5^{\text {th }}$ to $7^{\text {th }}$ of December, the coil currents were set to reversed direction to investigate any possible up/down asymmetries due to particle drifts between the upper and lower divertors. Due to instrument failure or poor plasma conditions, not all discharges during these experimental days have usable data. Of each available discharge, the spectral data were chosen from a central phase of $1 \mathrm{~s}$ in the ECRH power flat-top phase without fueling or impurity seeding. On experimental days only the helium discharges were performed (e.g. $15^{\text {th }}$ of November and $5^{\text {th }}$ of December), the $\mathrm{He} \mathrm{I} /\left(\mathrm{H}_{\alpha}+\mathrm{He} \mathrm{I}\right)$ ratio was above 0.77. During the experimental days when hydrogen and helium discharges took the turns (e.g. $14^{\text {th }}$ of November, $23^{\text {rd }}$ of November, $29^{\text {th }}$ of November and $6^{\text {th }}$ of December), frequent helium cleaning discharges caused helium particles trapped in the wall and slowly being released afterwards. A clear decrease of the $\mathrm{He} \mathrm{I} /\left(\mathrm{H}_{\alpha}+\mathrm{He} \mathrm{I}\right)$ ratio can be seen in helium discharges as well as in hydrogen discharges, especially after a series of hydrogen discharges without helium discharges in between, suggesting the helium can be easily replaced by hydrogen.

The hydrogen release in continuous helium discharges shows a downward trend over discharges, while higher hydrogen release can be seen with higher divertor $T_{\mathrm{e}}$, as seen in figure 11. In figure $11(\mathrm{a})$, the $\mathrm{H}_{\alpha} /\left(\mathrm{H}_{\alpha}+\mathrm{He} \mathrm{I}\right)$ ratio is plotted over a series of continuous helium discharges. The $\mathrm{H}_{\alpha} /\left(\mathrm{H}_{\alpha}+\mathrm{He} \mathrm{I}\right)$ ratio decreases over discharges, and the sudden increase of the $\mathrm{H}_{\alpha} /\left(\mathrm{H}_{\alpha}+\mathrm{He}\right.$ I) ratio at discharge No. 23 and discharge No. 27 are both companied by strong increase of divertor $T_{\mathrm{e}}$. The evolutions of divertor $T_{\mathrm{e}}$ and $n_{\mathrm{e}}$ over those helium discharges can be found in figure 4. Figure 11(b) shows that the $\mathrm{H}_{\alpha} /\left(\mathrm{H}_{\alpha}+\mathrm{He} \mathrm{I}\right)$ ratios increase with increasing divertor $T_{\mathrm{e}}$. The divertor $n_{\mathrm{e}}$ over those discharges are in the range of $(1.03-1.25) \times 10^{19} \mathrm{~m}^{-3}$ and slightly in inverse proportion to the divertor $T_{\mathrm{e}}$. No clear dependence of $\mathrm{H}_{\alpha} /\left(\mathrm{H}_{\alpha}+\mathrm{He}\right.$ I) ratio on divertor $n_{\mathrm{e}}$ is seen. Figures 11(c) and (d) show the 
helium release in continuous hydrogen discharges. The $\mathrm{He} \mathrm{I} /\left(\mathrm{H}_{\alpha}+\mathrm{He} \mathrm{I}\right)$ ratio increases with increasing divertor $T_{\mathrm{e}}$.

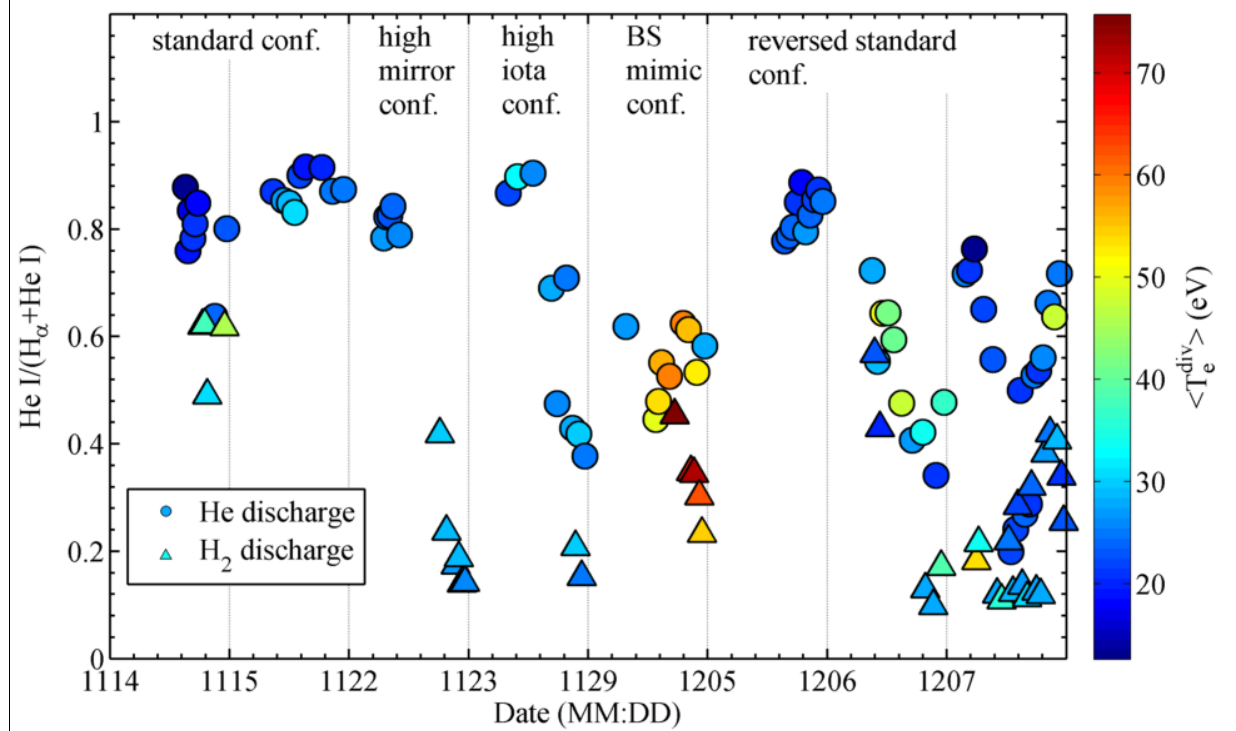

Figure 10. The evolution of particle flux ratio $\mathrm{He} \mathrm{I} /\left(\mathrm{H}_{\alpha}+\mathrm{He} \mathrm{I}\right)$ in helium and hydrogen discharges as a function of time from November $14^{\text {th }}$ to December $7^{\text {th }}$.
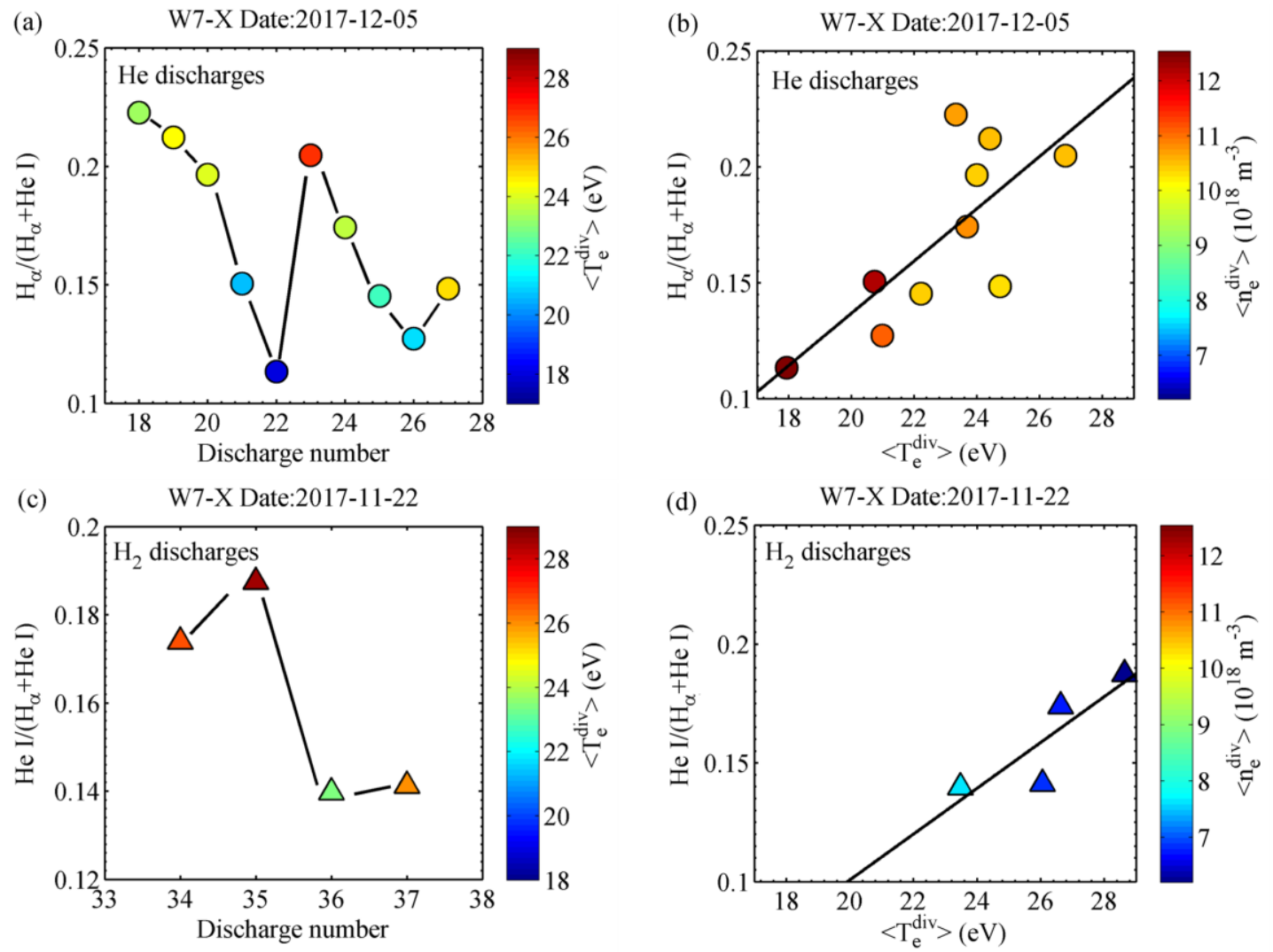

Figure 11. The particle flux ratio $\mathrm{H}_{\alpha} /\left(\mathrm{H}_{\alpha}+\mathrm{He} \mathrm{I}\right)$ over a series of continuous helium discharges (a) and the dependence of the $\mathrm{H}_{a} /\left(\mathrm{H}_{\alpha}+\mathrm{He} \mathrm{I}\right)$ ratio on the divertor temperature and density (b). The particle flux ratio $\mathrm{He} \mathrm{I} /\left(\mathrm{H}_{\alpha}+\mathrm{He} \mathrm{I}\right)$ over a series of continuous hydrogen discharges (c) and the dependence of the $\mathrm{He}$ $\mathrm{I} /\left(\mathrm{H}_{a}+\mathrm{He} \mathrm{I}\right)$ ratio on the divertor temperature and density (d). 
The carbon emission in the divertor region has been studied using low ionization stage spectral lines of carbon such as C II line $(\lambda=514.5 \mathrm{~nm})$. The C II particle flux is normalized to divertor $n_{\mathrm{e}}$ to enable the comparison of data over different configurations. Figure 12 shows the long time evolution of the normalized carbon influx $\mathrm{C} \mathrm{II} /\left\langle n_{\mathrm{e}}^{\mathrm{div}}\right\rangle$ in helium and in hydrogen discharges. Clearly lower levels of Carbon influx are seen in high mirror and high iota configuration. This is consistent with the connection length calculation in section 3.3, which shows very short connection length near the FOV, therefore only very small carbon influx can be expected. Figure 13 shows the normalized $\mathrm{C} \mathrm{II} /<n_{\mathrm{e}}^{\text {div }}>$ over divertor $T_{\mathrm{e}}$ in a series of continuous helium discharges and a series of continuous of hydrogen discharges. With divertor $T_{\mathrm{e}}$ raises, the normalized $\mathrm{C} \mathrm{II} /\left\langle n_{\mathrm{e}}^{\text {div }}\right\rangle$ increases, means more carbon influx with higher $T_{\mathrm{e}}$.

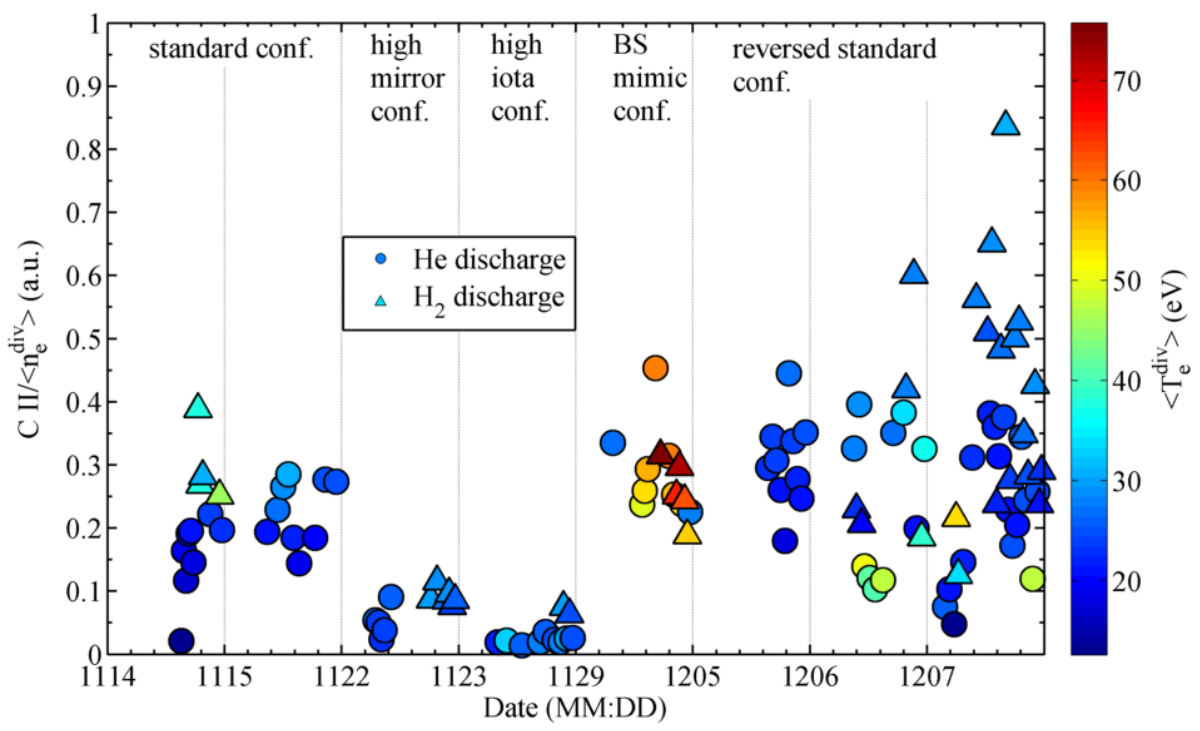

Figure 12. The evolution of the normalized particle flux $\mathrm{C} \mathrm{II} /\left\langle n_{\mathrm{e}}^{\text {div }}>\right.$ in helium and hydrogen discharges as a function of time from November $14^{\text {th }}$ to December $7^{\text {th }}$.
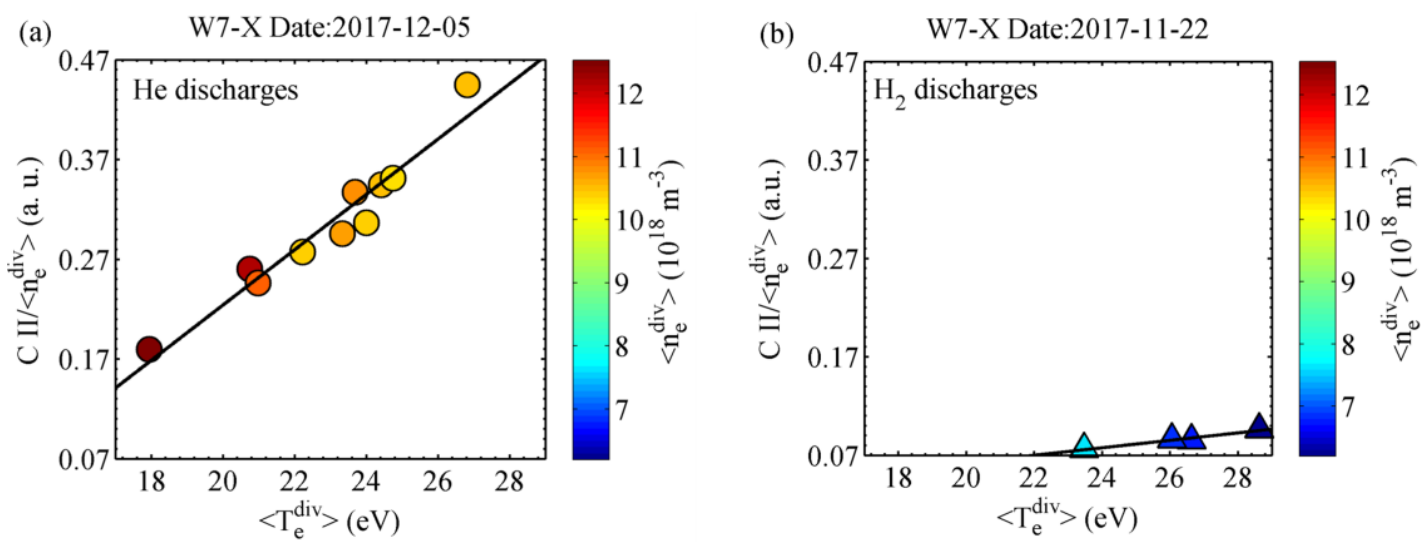

Figure 13. Parametric dependence of the normalized particle flux $\mathrm{C} \mathrm{II} /\left\langle n_{\mathrm{e}}^{\mathrm{div}}\right\rangle$ on divertor temperature and density for (a) a series of continuous helium discharges and (b) a series of continuous hydrogen discharges. The ranges of horizontal and vertical axes and the color bar range for divertor diversity are the same for the frames (a) and (b). The $\mathrm{C} \mathrm{II} /<n_{\mathrm{e}}^{\text {div }}>$ increases with increasing divertor $T_{\mathrm{e}}$. 
Strong oxygen emission was seen through the whole experiment campaign. The main suspects are the oxygen introduced into vessel by newly installed divertor components. As shown in figure 14, for experimental days on which only helium discharges were performed (e.g. $15^{\text {th }}$ of November and $5^{\text {th }}$ of December), the normalized $\mathrm{O} \mathrm{I} /\left\langle n_{\mathrm{e}}^{\text {div }}>\right.$ remain below 0.2 . On $14^{\text {th }}, 22^{\text {nd }}$ and $23^{\text {th }}$ of November, the $\mathrm{O} \mathrm{I} /\left\langle n_{\mathrm{e}}^{\text {div }}>\right.$ remain low in the helium discharges, and a higher $\mathrm{O} I /\left\langle n_{\mathrm{e}}^{\text {div }}\right\rangle$ is seen in the hydrogen discharges. On $29^{\text {th }}$ of November, the heat load on divertor targets was overload on purpose under the bootstrap mimic configuration. The divertor $T_{\mathrm{e}}$ went as high as $80 \mathrm{eV}$, and higher level of $\mathrm{O} \mathrm{I}$ flux is seen. On $7^{\text {th }}$ of December, the operational parameters change rapidly during the day, which cause rapid change of divertor emission levels over discharges and highest $\mathrm{O} I$ flux is seen in that day. Figure 15 shows the relation of the normalized particle flux $\mathrm{O} I /\left\langle n_{\mathrm{e}}^{\mathrm{div}}\right\rangle$ with the divertor temperature and density for a series of continuous helium discharges and a series of continuous hydrogen discharges. The normalized O I flux increases with increasing divertor $T_{\mathrm{e}}$.

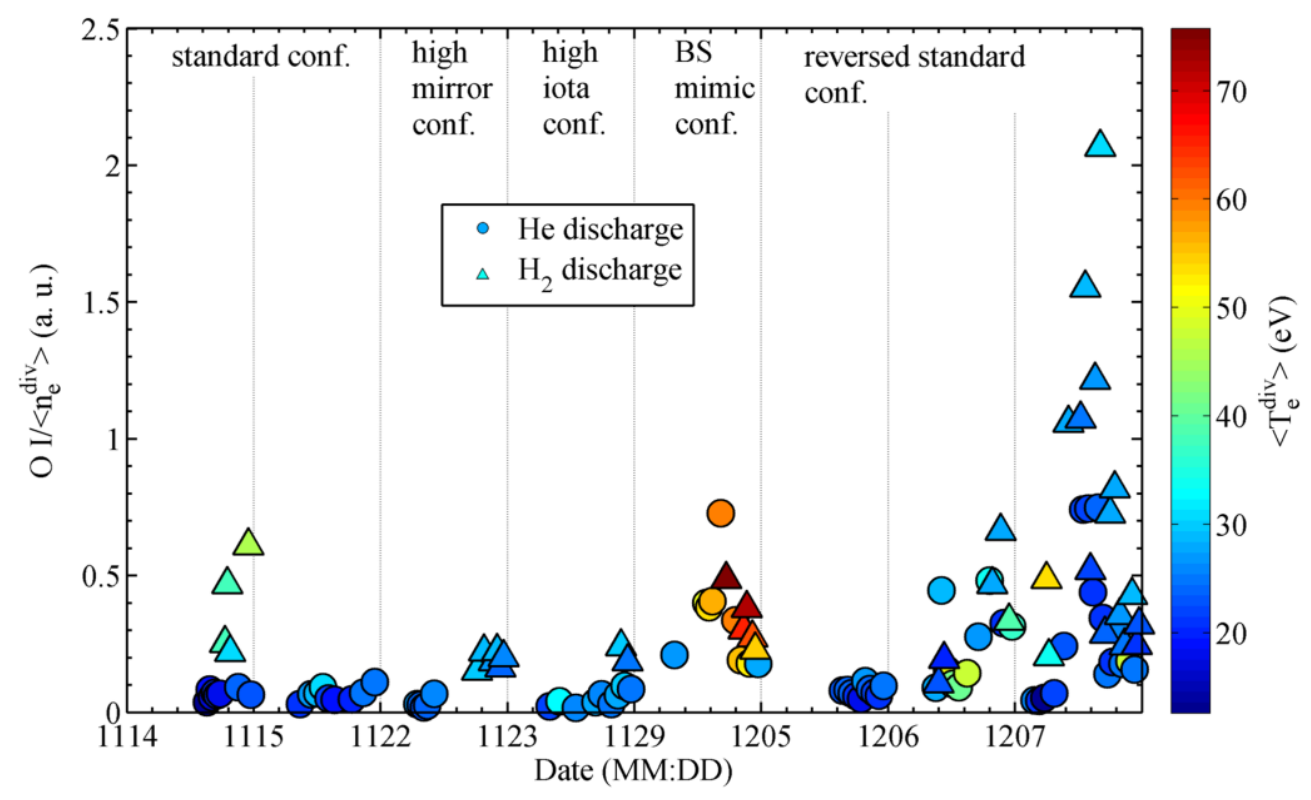

Figure 14. The evolution of the normalized particle flux $\mathrm{O} I /\left\langle n_{\mathrm{e}}^{\mathrm{div}}>\right.$ in helium and hydrogen discharges as a function of time from November $14^{\text {th }}$ to December $7^{\text {th }}$. 

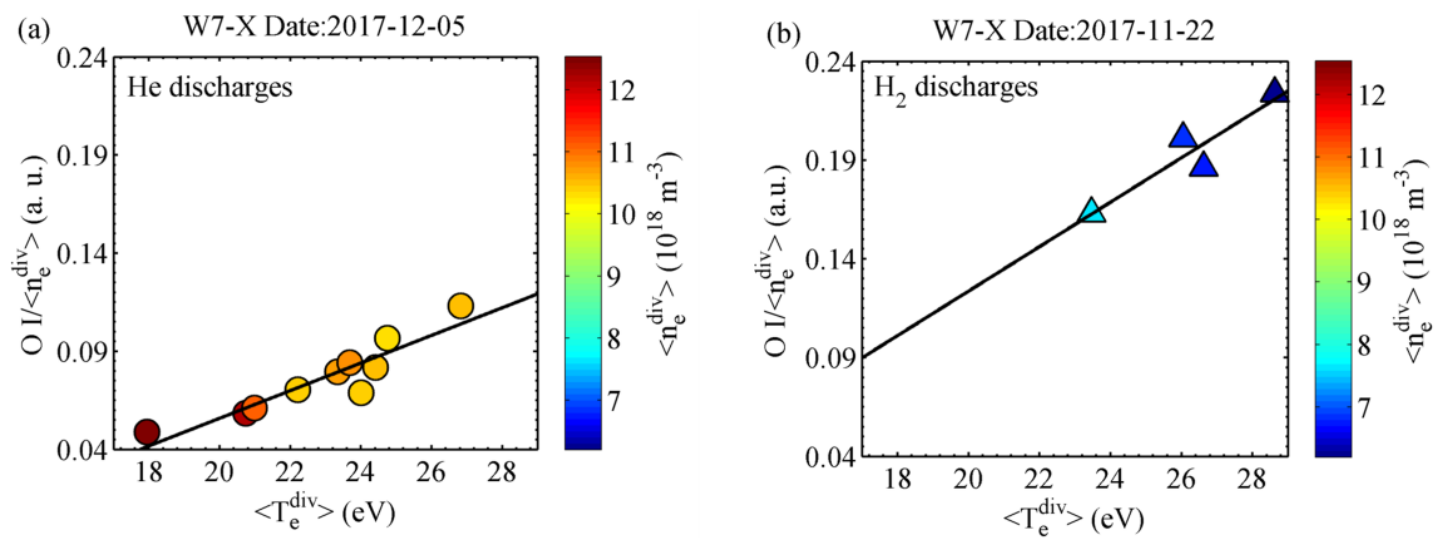

Figure 15. Parametric dependence of the normalized particle flux $\mathrm{O} \mathrm{I} /\left\langle n_{\mathrm{e}}^{\mathrm{div}}\right\rangle$ on divertor temperature and density for (a) a series of continuous helium discharges and (b) a series of continuous hydrogen discharges. The ranges of horizontal and vertical axes and the color bar range for divertor diversity are the same for the frames (a) and (b). The $\mathrm{O} \mathrm{I} /\left\langle n_{\mathrm{e}}^{\text {div }}\right\rangle$ increases with increasing divertor $T_{\mathrm{e}}$.

\section{Summary}

The fuel recycling and impurity behaviors in the divertor region during the W7-X first divertor operation phase (OP1.2a) have been investigated by using the divertor spectroscopy data. The spectral lines of the working gas hydrogen and helium, as well as the intrinsic impurities carbon, oxygen and iron were identified. Multiple neon and nitrogen lines were also identified during impurity seeding. Divertor electron temperature and density were measured from He I line intensity ratios, which is in good agreement with the divertor Langmuir probe data. The $\mathrm{H}_{\alpha}(656.3 \mathrm{~nm})$, He I $(587.6 \mathrm{~nm}), \mathrm{C}$ II $(514.5 \mathrm{~nm})$ and O I $(777.2$ $\mathrm{nm}$ ) line emissions are investigated over a wide range of operating conditions. Results show that the magnetic topology significantly affects the divertor emission level. The emission levels for $\mathrm{H}_{\alpha}$, He I, C II and O I decrease in the order of the standard configuration, the high mirror configuration and the high iota configuration, corresponding to the shrinkage of connection length, which resulting in a lack of sources near or inside the view of the divertor spectroscopy. The evolution of the $\mathrm{He} \mathrm{I} /\left(\mathrm{H}_{\alpha}+\mathrm{He} \mathrm{I}\right)$ influx ratio over hydrogen discharges and helium discharges shows that the plasma is actually a mixture of hydrogen and helium due to the strong recycling from wall regardless of the working gas type. The normalized influx $\mathrm{C}$ $\mathrm{II} /\left\langle n_{\mathrm{e}}^{\mathrm{div}}\right\rangle$ shows a clear dependence on the magnetic topology while the normalized influx $\mathrm{O}$ $\mathrm{I} /\left\langle n_{\mathrm{e}}^{\mathrm{div}}\right\rangle$ is more sensitive to the divertor $T_{\mathrm{e}}$. Analysis over a series of continuous helium discharges and a series of continuous hydrogen discharges shows that, with the divertor $T_{\mathrm{e}}$ increases, more hydrogen neutrals release from the wall in helium discharges and more helium neutrals release from the wall in hydrogen discharges. While the carbon influx and oxygen influx both increase with divertor $T_{\mathrm{e}}$. 


\section{Acknowledgments}

This work has been carried out within the framework of the EUROfusion Consortium and has received funding from the Euratom research and training programme 2014-2018 under grant agreement No 633053. The views and opinions expressed herein do not necessarily reflect those of the European Commission. The authors are thankful for the support from the China Scholarship Council. This work is also supported by National Natural Science Foundation of China (No. 11675050).

\section{References}

[1] Ehrenberg J et al 1989 J. Nucl. Mater. 162-164 63

[2] Federici G et al 2001 Nucl. Fusion 411967

[3] McCormick K et al 2011 J. Nucl. Mater. 415 S421

[4] Wolf R C et al 2016 IEEE Trans. Plasma Sci. 441466

[5] Feng Y et al 2004 Contrib. Plasma Phys. 4457

[6] Feng Y et al 2006 Nucl. Fusion 46807

[7] Feng Y et al 2009 Nucl. Fusion 49095002

[8] Feng Y 2013 J. Nucl. Mater. 438 S497

[9] Grigull P et al 2001 Plasma Phys. Controlled Fusion 43 A175

[10] Feng Y et al 2002 Plasma Phys. Controlled Fusion 44611

[11] Feng Y et al 2003 J. Nucl. Mater. 313-316 857

[12] McCormick K et al 2002 Phys. Rev. Lett. 89015001

[13] Ramasubramanian N et al 2004 Nucl. Fusion 44992

[14] Klinger T et al 2017 Plasma Phys. Controlled Fusion 59014018

[15] Peacock A et al 2009 Fusion Eng. Des. 841475

[16] Wei Y et al 2018 AIP Adv. 8085011

[17] Bosch H S et al 2013 Nucl. Fusion 53126001

[18] Geiger J et al 2010 Contrib. Plasma Phys. 50770

[19] Geiger J et al 2015 Plasma Phys. Controlled Fusion 57014004

[20] Barbui T et al 2016 Rev. Sci. Instrum. 87 11E554

[21] Krychowiak M et al 2016 Rev. Sci. Instrum. 87 11D304

[22] Atomic Data and Analysis Structure. http://www.adas.ac.uk/adaseu.php

[23] Schweer B, Brix M and Lehnen M 1999 J. Nucl. Mater. 266-269 673

[24] Goto M 2003 J. Quant. Spectrosc. Radiat. Transfer 76331

[25] Schmitz O et al 2008 Plasma Phys. Controlled Fusion 50115004

[26] de la Cal E 1998 Nucl. Instrum. Methods Phys. Res. A 403490

[27] de la Cal E and Guasp J 2011 Plasma Phys. Controlled Fusion 53085006

[28] Bozhenkov S et al 2013 Fusion Eng. Des. 882997

[29] Menmuir S, Kuldkepp M and Rachlew E 2006 Phys. Scr. 74439

[30] Morita S et al 2008 Plasma Fusion Res. 3 S1037 